\title{
Radiative Impact of Aerosols Generated From Biomass Burning
}

\author{
Sundar A. Christopher, Donna V. Vulcan and Ronald M. Welch \\ Institute of Atmospheric Sciences \\ South Dakota School of Mines and Technology \\ 501 E. St. Joseph Street \\ Rapid City, SD 57701-3995
}

Ph: 605-394-2291

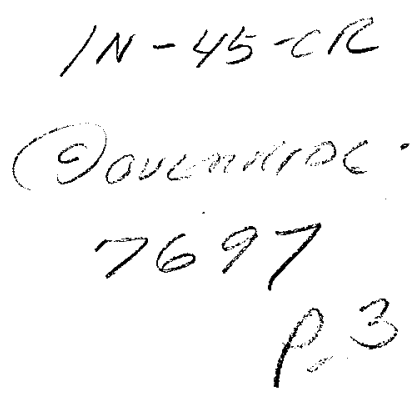

Abstract -- Atmospheric aerosol particles play a vital role in the earth's radiative energy budget. They exert a net cooling influence on climate by directly reflecting the solar radiation to space and by modifying the shortwave reflective properties of clouds. Each year, increasing amounts of aerosol particles are released into the atmosphere due to biomass burning, dust storms, forest fires and volcanic activity. These particles significantly perturb the radiative balance on local, regional, and global scales. While the detection of aerosols over water is a well established procedure, the detection of aerosols over land is often difficult due to the poor contrast between the aerosols and the underlying terrain. In this study, we use textural measures in order to detect aerosols generated from biomass burning over South America, using AVHRR data. The regional radiative effects are then examined using ERBE data. Preliminary results show that the net radiative forcing of aerosols is about $-36 \mathrm{~W} / \mathrm{m}^{2}$.

\section{INTRODUCTION}

Atmospheric aerosol particles, both natural and anthropogenic, are important to the earth's radiative energy balance. They scatter the incoming solar radiation and modify the shortwave reflective properties of clouds by acting as cloud condensation nuclei (CCN). Although it has been recognized that aerosols exert a net cooling influence on climate [1], this effect has received much less attention than the radiative forcings due to clouds and greenhouse gases. The radiative forcing due to aerosols is comparable in magnitude to current anthropogenic greenhouse gas forcing but opposite in sign [2]. One contributing factor for the inability of current climate models to accurately estimate surface temperatures may be due to the inaccurate characterization of aerosol effects. In order to obtain accurate estimates of aerosol perturbations on the earth's radiation balance, it is imperative to include the influence of aerosols in climate models. This will enable us to predict potential future climate changes more confidently. However, first we must obtain realistic global estimates of aerosol radiative effects before reliable parameterizations can be made.
Biomass burning, which is widely prevalent in the tropics [3], serves to clear land for shifting cultivation and the expanding population. It produces large amounts of trace gases and aerosol particles which play a pivotal role in tropospheric chemistry and climate [4]. The aerosol particles emitted from biomass burning are a major source of cloud condensation nuclei, affecting the microphysics of boundary layer clouds and altering the radiation budget of the earth by increasing the albedo [5]. Recently, Penner et al. [6] proposed that smoke from biomass burning may have a significant impact on the global radiation balance. They estimate that $114 \mathrm{Tg}$ of smoke is produced per year in the tropics through biomass burning. From their analysis, they conclude that the effects of smoke aerosol due to biomass burning may exert a net cooling effect as large as $2 \mathrm{~W} / \mathrm{m}^{2}$.

In this study, 32 selected satellite images of South America are analyzed during the biomass burning season by using a new aerosol detection scheme based on textural measures.

\section{DATA}

In this project, the Advanced Very High Resotution Radiometer (AVHRR), Local Area Coverage (LAC) data is used to detect aerosols generated from biomass burning, The nominal resolution of the AVHRR LAC data is about $1.1 \mathrm{~km}$ and it has five spectral channels. In order to study the radiative properties of the aerosol particles, the ERBE instantaneous scanner data is used. The nominal resolution of the ERBE data is about $40 \mathrm{~km}$ and the radiances are converted to TOA fluxes using a scene dependent bidirectional reflection model [7].

\section{METHODOLOGY}

In this study, we use spectral and textural measures to identify aerosols. Texture is often interpreted in the literature as a set of statistical measures of the spatial distribution of gray levels in the images. The Gray Level Difference Vector (GLDV) method is used to compute several textural features [8]. The GLDV method assumes that the textural 
information in an image is contained in the overall spatial relationship the gray levels in the image have to one another. GLDV is based upon the absolute difference between pairs of gray levels $i$ and $j$ found at a distance $d$ apart at angle $\phi$ with a fixed direction. Several textural measures were computed, including contrast, local homogeneity, angular second moment, entropy, mean difference cluster shade, and difference cluster prominence. An example of the mean textural feature calculated for one of the analyzed images is shown in Fig. 1.

The ERBE scanner data used in this study has a nominal spatial resolution of about $40 \mathrm{~km}$, and the AVHRR data has a nominal spatial resolution of about $1.1 \mathrm{~km}$ in the LAC form. Both radiometers scan the earth in a cross-track direction which allows for simultaneous and coincident measurements. In this study, we use a collocation procedure similar to that of $\mathrm{Li}$ and Leighton [9]. First the center of the ERBE pixel that is closest to the center of the AVHRR pixel is identified. Once the center pixel has been identified, a group of $37 \times 37$ AVHRR pixels centered on the closest pixel is assumed to correspond with an ERBE pixel.

In this study, the ERBE SW fluxes versus the AVHRR channel 1 reflectance are correlated. Figure 2 shows a typical plot between ERBE and AVHRR measurements in the Amazon area, with a correlation coefficient of $97 \%$.

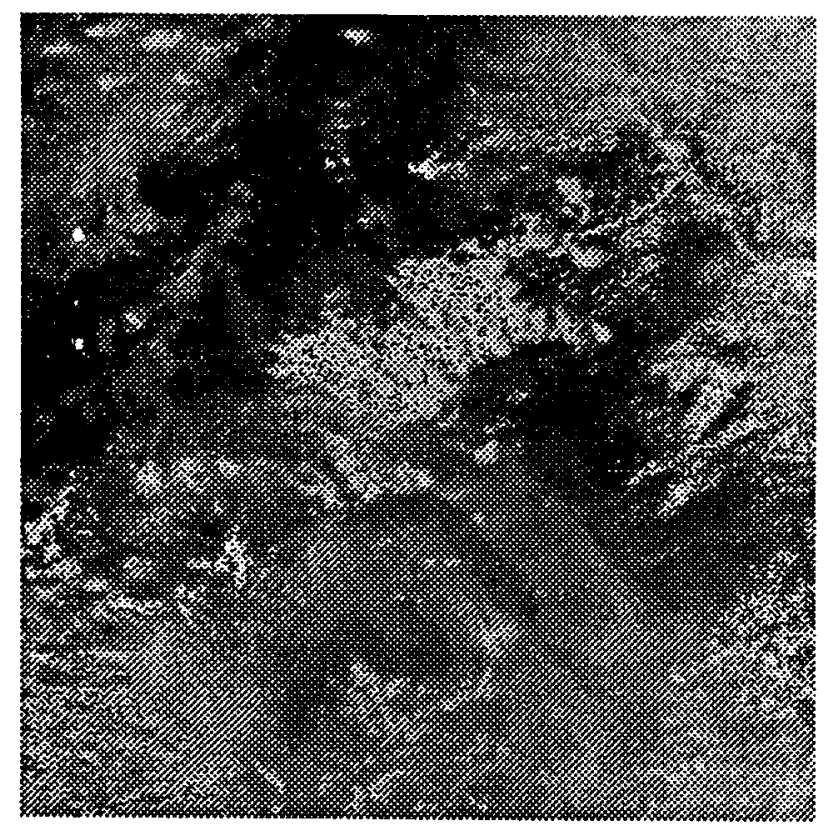

Fig. 1: AVHRR LAC image over South America, Rondonia Province (Sept 3, 1985). Overlay: red - chl; green - ratio14; blue - MEAN (ratio14).

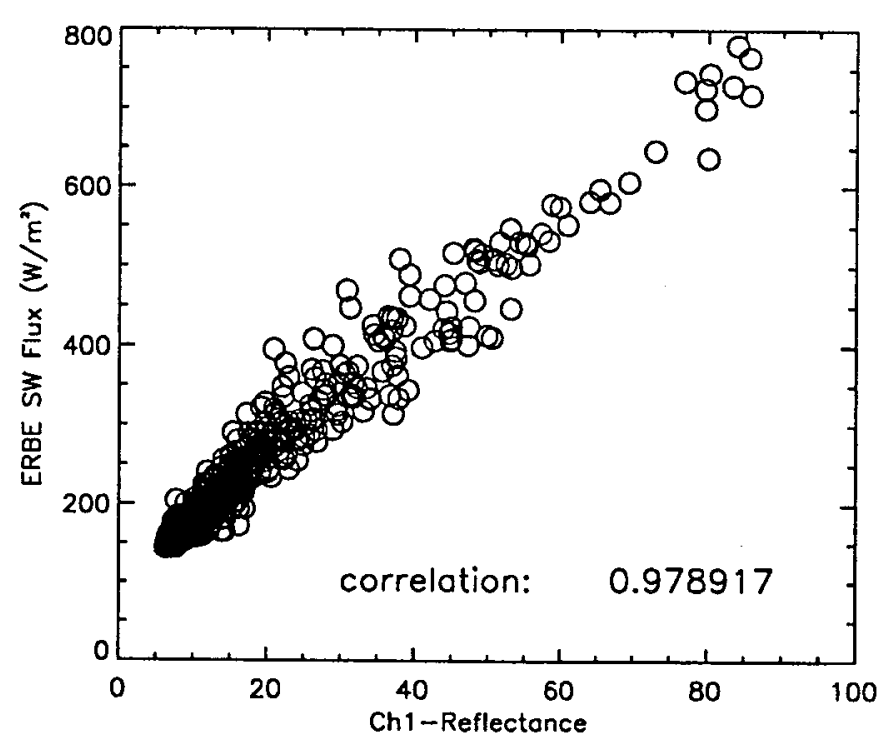

Fig. 2: Collocation between AVHRR and ERBE: AVHRR channel 1 reflectance vs. ERBE SW flux.

\section{RESULTS}

The selected satelltite images of South America during the burning seasons of 1985,1986 , and 1987 have been examined in order to identify the aerosols generated from biomass burning, as well as to study their effect on the top of the atmosphere fluxes.

The collocation analysis was performed only for the 1985 and 1986 data, since ERBE data is not available for 1987. Figure 1 shows our preliminary results. This image is about $700 \mathrm{~km}^{2}$. The three-band overlay has channel 1 in red, the ratio of channel 1 and channel 4 in green, and in blue the MEAN of the ratio. The detection of acrosols over land gave the best results when combining spectral measures with textural features such as mean and angular second moment. The fire detection was done using the same criteria as Kaufman et al. [10]. A total of 9,034 fires were detected in this scene.

Understanding the influence of clouds on the earth radiation budget is important for understanding the earth's climate. The difference in the radiative heating between a column of clear and cloudy air is called cloud radiative forcing [11]. Similarly we calculated the aerosol radiative forcing by subtracting the "smoky" air from the column of clear air. Figure 3 shows preliminary results obtained in this study. The TOA flux for the clear air varied from 93 to $166.6 \mathrm{~W} / \mathrm{m}^{2}$; cloud air had a minimum of $240.6 \mathrm{~W} / \mathrm{m}^{2}$ and a maximum of $780.6 \mathrm{~W} / \mathrm{m}^{2}$; and the smoke covered areas had a corresponding TOA flux varying from 133.2 to $221.6 \mathrm{~W} / \mathrm{m}^{2}$. The net radiative forcing for aerosols was determined to be $-36.15 \pm 14.20 \mathrm{~W} / \mathrm{m}^{2}$. 


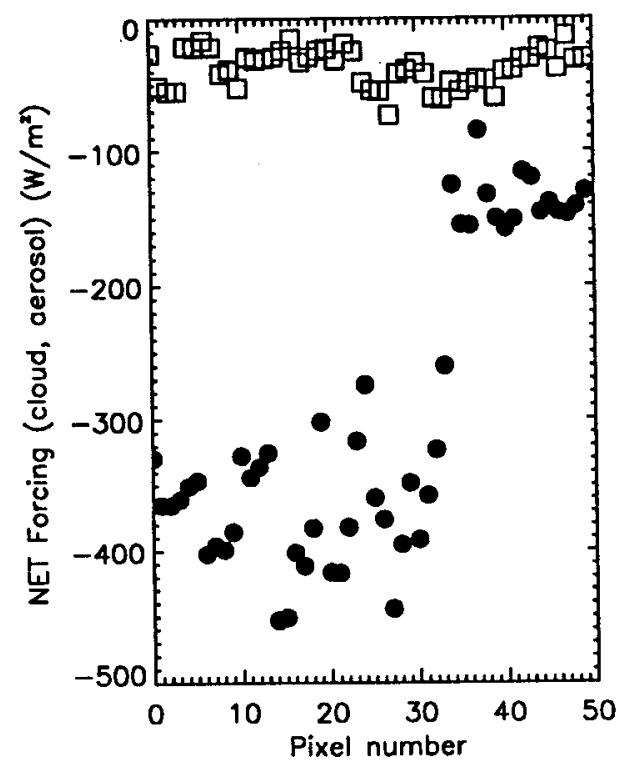

Fig. 3: Net radiative forcing (squares for smoke, filled circles for cloud). Each sample covered $37 \times 37 \mathrm{~km}^{2}$ area.

\section{SUMMARY}

Aerosols play a crucial role in the radiative balance of the earth-atmosphere system. While the detection of aerosols over water is relatively straight forward, the detection of aerosols over land is often difficult due to the high albedo of the background. In this study, we use the spatial information of AVHRR LAC imagery to accurately detect aerosols produced from biomass burning. Several textural measures were computed and the best results were obtained using mean and angular second moment. The selected images were analyzed in order to determine the regional radiative impact of aerosols generated by biomass burning. Our preliminary results show that the net radiative forcing of aerosols is about $-36 \mathrm{~W} / \mathrm{m}^{2}$.

\section{ACKNOWLEDGMENTS}

This research was supported under NASA Grant NAG W-3740. We thank Dan Baldwin for the navigation software and Joie Robinson for typing the manuscript.

\section{REFERENCES}

[1] S.A. Twomey, M. Piepgrass and T.L. Wolfe, "An assessment of the impact of pollution on the global albedo," Tellus, vol. 36b, pp. 356-366, 1984.
[2] J.T. Houghton, G.J. Jenkins and J.J. Ephraums, eds., "Climate Change: The IPCC Scientific Assessment," Report for the Intergovernmental Panel on Climate Change, Cambridge Univ. Press, Cambridge, 362 pp., 1990.

[3] Y.J. Kaufman and T. Nakajima, "Effect of Amazon smoke on cloud microphysics and albedo-analysis from satellite imagery," J. Appl. Meteor., vol. 32, pp. 729-744, 1993.

[4] P.J. Crutzen and M.O. Andreae, "Biomass burning in the tropics: Impact on atmospheric chemistry and biogeochemical cycles," Science, vol. 250, pp. 1669-1678, 1990.

[5] J.A. Coakley, Jr., R.D. Cess and F.B. Yurevich, "The effect of tropospheric acrosol on the earth's radiation budget: A parameterization for climate models," J. Atmos. Sci., vol. 40, pp. 116-138, 1983.

[6] J.E. Penner, R.E. Dickinson and C.A. O'Neill, "Effects of aerosol from biomass burning on the global radiation budget," Science, vol. 256, pp. 1432-1433, 1992.

[7] R.M. Welch, S.D. Sengupta and D.W. Chen, "Cloud field classification based upon high spatial resolution textural features. Part I: Gray level cooccurrence matrix approach," J. Geophys. Res., vol. 93, pp. $12,663-12,681,1988$.

[8] J.T, Suttles, R.N. Green, P. Minnis, G.L. Smith, W.F. Staylor, B.A. Wielicki, I.J. Walker, D.F. Young, V.R. Taylor and L.L. Stowe, "Angular radiation models for earth-atmosphere system, Vol. I: Shortwave radiation," NASA Ref. Publ. 1184, 147 pp., 1988.

[9] Z. Li and H.G. Leighton, "Scene identification and its effect on cloud radiative forcing in the Arctic," J. Geophys. Res., vol. 96, pp. 9175-9188, 1991.

[10] Y.J. Kaufman, C.J. Tucker and I. Fung, "Remote sensing of biomass burning in the tropics," J. Geophys. Res., vol. 95, pp. 9927-9939, 1990.

[11] P. Minnis, B.R. Barkstrom, E. Ahmad and D. Hartmann, "Cloud-radiative forcing and climate: Results from the Earth Radiative Budget Experiment," Science, vol. 243, pp. 57-63, 1989. 
......... 